\section{“Compartir la vida”. En torno a la adopción de las redes sociales en Internet entre las personas con discapacidad y mayores}

\author{
"Sharing life". About the adoption of social \\ networks on the Internet among people with \\ disabilities and older persons
}

\begin{abstract}
Resumen
Las redes sociales en Internet, en conjunción con nuevos dispositivos como el teléfono inteligente o la tableta -evoluciones del PC que se han convertido en una extensión del individuo- recrean las formas de relacionarnos. El presente artículo, desde un enfoque sociológico de la tecnología, ofrece un acercamiento a las prácticas y, en especial, a los procesos de representación discursiva de estas redes entre las personas con discapacidad y mayores, para entender las diferentes actitudes ante ellas, las barreras percibidas, los distanciamientos y su potencial descubierto. Se constata que, además de los perfiles de diversidad funcional, la edad y el nivel formativo condicionan en gran medida las vías de adopción de estas tecnologías de la información y la comunicación (TIC) y el efecto de sus barreras y el aprovechamiento de sus ventajas.
\end{abstract}

\section{Palabras clave}

Discapacidad, participación, redes sociales, Internet.

\begin{abstract}
Social networking on the Internet, in conjunction with new devices like the smartphone or tablet -evolutions of the PC which have become an extension of the individual- recreate the ways of being in contact. This article offers, from a sociological approach to technology, an approximation to practices and, especially, to the processes of discursive representation of these networks between people with disabilities and elderly, to understand the different attitudes to them, barriers perceived, the distances and its disclosed potential. It is found that, in addition to the functional diversity profiles, age and educational level largely condition the process of adoption of these information and communications technologies (ICTs), the effect of its barriers and the use of their advantages.
\end{abstract}

\section{Keywords}

Disability, participation, social networks, Internet.

\section{Luis Miguel Bascones \\ Serrano}

<lmbascones@technosite.es>

Dpto. de Estudios e Investigación Social, Technosite

\author{
Para citar: \\ Bascones Serrano, L. M. (20I4): \\ "'Compartir la vida'. En torno \\ a la adopción de las redes sociales \\ en Internet entre las personas \\ con discapacidad y mayores". \\ Revista Española de Discapacidad, \\ 2(I): I75-I9I. \\ <http://dx.doi.org/IO.5569/2340- \\ 5 IO4.02.OI.IO>
}

Fecha de recepción: 30-I 2-20I3 Fecha de aceptación: 27-05-20I4 


\section{Introducción}

"Sólo lo fugitivo permanece" Francisco de Quevedo

Las redes sociales en Internet, como punta de lanza de la Web 2.0 -y de la sociedad de la información- adquieren una implantación y dinamismo vertiginosos en los últimos años, junto con el auge de los teléfonos inteligentes, las tabletas y las tarifas planas ${ }^{\mathrm{I}}$. Se trata de una combinación de herramientas que, por el salto de sus funcionalidades y el cómo de sus engranajes comunicativos, evoca la tesis de Marshall McLuhan "el medio es el mensaje": recrea la cultura social, con nuevos modos de pensar, percibir, expresarnos y relacionarnos, nuevas y cambiantes formas de ser-en-el-mundo. El límite de I40 caracteres en los tuits de Twitter y el "bocadillo" de respuesta a la pregunta sobre el estado “¿Qué estás pensando?”, concebido para micropost en Facebook, con su actualización constante y fluir como un río, parecen cambiar las lógicas de acceso y consulta de la información y del intercambio de mensajes personales, de los diálogos y la presentación biográfica del yo-público-ideal, apoyado con frecuencia en la imagen, en la fotografía.

Para las personas con discapacidad, las plataformas de red parecen multiplicar las ventajas y oportunidades, y por otro lado, traen consigo barreras específicas, de accesibilidad. Bajo el paraguas de las redes sociales en Internet, se han encontrado diferentes patrones de uso que se corresponden, por una parte, con los diferentes perfiles de diversidad funcional (es

I. Según formulaba Eduardo Bericat ya en I996, "la combinación 'Ordenador-Y-Red', la tecnoestructura social de 'Ordenadores En Redes' definen tecnológicamente la sociedad de la información. El ordenador aporta el componente individualista, y supone una clara extensión operativa del organismo humano. La Red, componente holista y relacional de la nueva sociedad, procura su infraestructura de interacción. Entendiendo la naturaleza básica y el posible uso social de estos dos útiles, estaremos en disposición de reflexionar autónomamente sobre los cambios sociales implicados y sobre el modelo social que pueda derivarse de los mismos" (Bericat, I996: 99). muy distinta la forma de utilizar las redes por parte de los usuarios con ceguera que con discapacidad visual o cognitiva, por ejemplo), con la edad -parecen compartir las prácticas de su grupo generacional ${ }^{2}-\mathrm{y}$ también con el nivel formativo y económico. Además, se cruzan las diferentes actitudes y orientaciones culturales respecto a la tecnología y la sociabilidad. El presente artículo plantea un acercamiento a estas cuestiones ${ }^{3}$.

El estudio de caso se basa en un enfoque sociológico de la tecnología y su apropiación (Echeverría, 2008). En términos de método, se observan las representaciones discursivas, con especial atención a cómo se vive, se significa $\mathrm{y}$, en consecuencia, se afrontan estrategias ante una experiencia nueva, la interacción a través de las plataformas de red en Internet, a partir de experiencias previas, es decir, a las operaciones de isomorfismo que están en la raíz de los procesos metafóricos (Lakoff y Johnson, I995). Un acercamiento, en otras palabras, a los modelos mentales, desde la perspectiva de evaluación de la experiencia de usuario (CalvoFernández et al., 20II).

Tras la ficha metodológica, se aborda el sentido de equiparación y autonomía personal que ha

2. Al leer la publicación Transformemos el ocio digital (Pascual y Santero, 20I0), sobre la apropiación y uso entre los jóvenes de las redes sociales en Internet, de la mensajería instantánea y la comunicación móvil, se observan pautas comunes con los resultados del presente estudio referidos a los más jóvenes. Sin embargo, hay usos y un sentido diferente en determinados perfiles de discapacidad, y también barreras que dificultan su disfrute.

3. Este texto se basa en los resultados del proyecto Participación de las Personas con Discapacidad en las Redes Sociales en Internet, iniciativa de la Fundación ONCE. El principal objetivo del proyecto se orienta a conocer la realidad de los usuarios con discapacidad al emplear las redes sociales en Internet, de cara a ampliar y normalizar sus posibilidades de comunicación, visibilidad e interacción social. Mari Carmen García Fernández coordinó el proyecto, en el que participaron Verónica Martorell, Miguel Gainzarain (investigadores sociales) y Raúl Vara (trabajador social), además del autor, a cargo del análisis del trabajo de campo y redacción del informe base del presente artículo. Como resultado del proyecto, se publicó el portal "Enredar. Guía de Ayuda para las Redes Sociales", disponible en <http:// www.enredar.fundaciononce.es/>. También se presentó un resumen en la Jornada Técnica "Redes sociales y discapacidad: oportunidades y retos" (I6/02/I2), organizada por la Fundación ONCE con apoyo de Technosite. 
implicado Internet y cómo se proyecta a las plataformas de red en Internet para las personas con discapacidad. En segundo lugar, se esbozan las vías de comienzo y las principales prácticas identificadas en relación con estas redes. En tercer lugar, se analizan los ejes discursivos y campos metafóricos relacionados con esta tecnología, incluyendo los distanciamientos. En los tres años transcurridos desde la investigación empírica y el momento actual, las tecnologías y las prácticas han cambiado, en especial por un mayor acceso a las redes sociales desde los dispositivos móviles y sus aplicaciones nativas. Se ofrece una contextualización desde el presente, para terminar con una serie de consideraciones y preguntas.

\section{Metodología}

La investigación se ha basado en la realización de seis grupos de discusión, integrados por un total de 45 participantes, cuya muestra contempló las siguientes variables:

- Perfil de diversidad funcional: visual, auditiva, motriz e intelectual.

- $\quad$ Edad: se procuró combinar diferentes edades (entre los 25 y los 64 años) en cuatro de los grupos, además de realizar un grupo formado por menores de 25 años con discapacidad y otro por mayores de 64 ( $\mathrm{sin}$ discapacidad aparente).

- Sexo.

- Distinto nivel de conocimiento y uso de Internet.

La selección de integrantes de los grupos se llevó a cabo a través de la red de contactos formales e informales, así como del panel de usuarios de participantes en diferentes proyectos de Technosite. Se aplicó una conducción de discurso libre a partir de guiones semiestructurados. Las sesiones se celebraron Madrid, durante marzo y abril de 20 I I. Se llevó a cabo un análisis sociológico del discurso.

\section{3. "Todos iguales ante la pantalla": valores específicos de Internet y las redes sociales}

El uso de las tecnologías de la información y la comunicación (TIC) [ordenador, teléfonos móviles, etc.] y, en concreto, de Internet implica valores específicos para las personas con discapacidad. En primer lugar, al sustituir materiales en soporte físico (papel, tinta) por contenidos digitales, a los que se puede acceder sin necesidad de realizar operaciones de manipulación -sin ir más lejos, el que escribe estas líneas es tetrapléjico y usa un programa de reconocimiento de voz-o requerir del sentido de la vista. Permite realizar operaciones con autonomía, evita la dependencia de terceros para el acceso a la información. Piénsese, por ejemplo, en poder leer por sí mismo las facturas y movimientos en las cuentas del banco, que antes venían sólo en tinta.

A pesar de los avances, el medio arquitectónico sigue presentando múltiples barreras para los desplazamientos y también para la entrada a locales comerciales, como una agencia de viajes o una oficina bancaria, y realizar allí "físicamente" los trámites. Internet posibilita resolver gestiones sin la necesidad de realizar desplazamientos. No es ya que se facilite la participación social, sino que simplemente se vuelve posible: a pesar de sus barreras, las TIC han abierto, por su flexibilidad, nuevas opciones para acceder con autonomía a la formación, al trabajo, a la información, al consumo, a las relaciones interpersonales, al activismo asociativo y político, etc. Las TIC e Internet se han convertido ya en una herramienta efectiva de equiparación, de democratización y de vida independiente. El sentido de ser uno más, “igual ante la pantalla”, está ampliamente extendido y arraigado entre los participantes, en especial entre aquellos usuarios con un nivel formativo intermedio o alto, o en todo caso, una mayor familiaridad con estas tecnologías. Este valor se tiende a trasladar a las plataformas de red social:

"Porque igual que te la facilita para trabajar, el ordenador digamos que democratiza un poco 
el trabajo, porque ya no es tanto la barrera física a la hora de realizar ciertas tareas. Es una herramienta también muy útil para no tener la dependencia de estar físicamente para muchas cosas. Entonces, es una herramienta virtual que, aplicada a tu mundo real, es muy útil. Luego, en su uso como tal, tú eres un usuario más en una red" (GD 3. Participante con discapacidad física).

Las TIC facilitan a las personas con sordera acceder a la información con autosuficiencia ("un móvil me da la oportunidad de informarme, igual que otras personas usan la radio") y multiplicar los recursos para la comunicación interpersonal, como crear y encontrarse en un punto. Sustituye a medios convencionales que requerían del oído, como el teléfono u otros contenidos audiovisuales.

En contrapartida, la sociedad de la información, o del conocimiento, puede entrañar una selva (por saturación) de contenidos, hasta el punto de conducir al bloqueo a quienes tienen dificultades para la atención y desenvolvimiento en entornos informativos complejos o cambiantes, sobre todo a personas con discapacidad cognitiva y autismo, también a mayores. Puede situarlas en clara desventaja si carecen de las adecuaciones necesarias, sobre todo de claridad y disposición "amigable".

Por otra parte, es necesario recordar cómo distintos perfiles de usuarios hacen un uso diferenciado de las tecnologías a la hora de consultar contenidos, incluyendo, en algunos casos productos de apoyo específicos: lectores de pantalla entre las personas con ceguera, zoom, programas de reconocimiento de voz, etc. Los mayores requieren soluciones de accesibilidad y facilidad de uso en sus diferentes vertientes para desenvolverse con autonomía en la Red.

Las redes sociales en Internet (RSI) multiplican el potencial que ya se venía atribuyendo a la Red, tanto en el acceso a la información como en las interacciones comunicativas. Pese a este mayor potencial, el cambio vertiginoso en las funcionalidades, escasa accesibilidad, el riesgo de equivocarse, además de las amenazas percibidas en cuanto a intromisión en la privacidad, también suscitan reservas y frenos.

\section{Los comienzos}

En este apartado se habla de los impulsores iniciales, los prescriptores y motivo de elección determinadas plataformas de red social sobre otras.

\subsection{Impulsores para dar el salto}

Las redes sociales en Internet se perciben como un paso más dentro de aplicaciones ya existentes en este medio, como los videojuegos colectivos, el correo electrónico y los programas de mensajería y videoconferencia (Messenger, Skype) y nuevas funcionalidades “2.0”, como la aplicación de encuestas Doodle.com. Una red social, al decir de los participantes en el estudio, vendría a facilitar la comunicación entre personas en tiempo real. Además, desde el primer momento surgen características como la simetría o el compartir un punto de interés común.

Estas fronteras difusas respecto a aplicaciones previas, junto a las nuevas funcionalidades de las RSI, como publicar y compartir en un espacio común contenidos multimedia, impulsan el salto a estas plataformas. Pero aunque se apuntan razones de tipo tecnológico, los principales impulsores para abrir una red social virtual son de tipo social: giran en torno la moda y al sentido práctico que, para comunicar, da la masa crítica de usuarios (tu red social) en una determinada plataforma.

En distintos momentos se empleó el significante “moda" como la idea de opción influenciada por un entorno social, más amplio o más próximo, donde la participación en las redes sociales encuentra su fundamento y expresión: para formar parte de la corriente y el vértice de la novedad tecnológica, del valor de lo nuevo, para no quedarse atrás o al margen. La presión 
social de la moda se relaciona con fenómenos sociales referidos a la visibilidad pública de Facebook/Twitter, tanto en las noticias -por ejemplo, acerca de su papel como catalizadores en los países de la "primavera árabe", como hasta en una película cinematográfica sobre la red Facebook, en cartel durante las fechas de celebración de los grupos. Entre quienes toman distancia respecto a las RSI -y buena parte de los mayores se sitúan entre ellos-, se califica como un paso innecesario, dadas las anteriores aplicaciones para la comunicación disponibles-, un capricho pasajero:

"No lo veo cosa del otro mundo, cuando hay correos y hay otras cosas, pero ahora es muy moderno y estamos ahí" (GD 5. Mayores activos).

Los más jóvenes son, sin duda, el público más sensible a la dinámica de la moda, hasta vencer resistencias, como la falta de accesibilidad o las dudas ante el posible uso indebido de la información personal publicada. Abrir una cuenta en una red social se convierte en la forma de afianzar esta pertenencia, de no quedar fuera de la comunidad:

\footnotetext{
"Cuando empezamos pocos amigos, ahí empecé yo, y ya el año pasado, fuimos muchísimos. Ahora, actualmente estamos todos en el Tuenti” (GD 6. Jóvenes con discapacidad).
}

El perfil o cuenta de una red social virtual se convierte en la tarjeta de presentación que se facilita a alguien a quien acabas de conocer, por ejemplo, en la calle o en una discoteca. Es la vía de contacto que ha ido sustituyendo en esta función, primero, al teléfono móvil, y después, al Messenger.

La gratuidad -en otras palabras, el hecho de estar incluido el uso de la red social en la contratación de tarifas planas de Internet, tanto vinculadas a líneas fijas (ordenador) como, cada vez en mayor medida, a la telefonía móvil-supone otra ventaja para mantener la comunicación con "los próximos" sin gastar en una llamada telefónica.

\section{2. ¿Dónde está tu red? Prescriptores y espacio de pertenencia}

Lo habitual es abrir una cuenta en una u otra red virtual según la elección mayoritaria en nuestra red ya existente offline. La invitación puede ser en algunos casos directa, y de quién provenga depende en buena medida de la edad. En el caso de los jóvenes, la influencia del grupo de pares respecto al cual se desea una pertenencia normalizada resulta determinante en la selección de una plataforma de red:

\footnotetext{
"Yo empecé a meterme al Facebook porque mis amigas me aconsejaron, me explicaron cómo era, y al principio dije que era un poco complicado, pero luego poco a poco me fue gustando y me entero de muchas informaciones, de muchas cosas y cada vez me va gustando más y estoy contenta” (GD 2 . Discapacidad auditiva).
"Yo, básicamente, porque la gente que conozco utiliza ésas, y no me hace falta estar complicándote la vida” (GD 6. Jóvenes con discapacidad).

Entre los mayores, la iniciativa de abrir una cuenta en redes sociales en Internet suele surgir a instancias de los hijos/as, que son quienes directamente suelen abrirla y dejarla configurada, introduciendo de manera simultánea a sus padres/ madres respecto a las nociones básicas para su uso. Se abre la red en la que ya están inscritos los hijos o la pareja, aquélla a través de la cual se va a mantener la comunicación, ya sea (sobre todo) Twitter o Facebook. En este grupo etario, se manifiesta en ocasiones cierta resistencia o sentido de transición obligada: puede no verse al principio la utilidad añadida de las redes sobre otras aplicaciones anteriores o que se siguen usando. Luego se descubren otros usos, como la información, el ocio y el encuentro con amistades.

Aunque en un primer momento, sobre todo aquéllos con mayor conocimiento y afición por Internet, podrán abrir, con ánimo exploratorio, diferentes redes, a medio plazo la actividad tiende a concentrarse sobre una o dos de ellas. 
La red basa su valor en la sociabilidad, en el mayor número de "amigos" o "contactos" que se puedan alcanzar o añadir. Por este "efecto Mateo" (“a quien más tiene, más se le dará”) cabría augurar escaso éxito a las plataformas de red que se mantengan en niveles minoritarios de implantación, como algunas iniciativas temáticas, entre las que cabe mencionar las redes virtuales especializadas en discapacidad. Sin embargo, en estos años se constata que se afianzan en su nicho redes especializadas, que cumplen con una finalidad específica (como Meetic, de acuerdo con el estudio de Tomé y Soto [cit. en Huertas, 20I4]), entre otras en torno al coleccionismo, la compra/venta, compartir viajes, etc.

\subsection{La elección por accesibilidad y facilidad de uso}

La accesibilidad es una de las primeras preocupaciones y motivos de elección o preferencia de una red sobre otras, sobre todo en el caso de las personas ciegas ${ }^{4}$. Así, las personas con ceguera tienden a decantarse de manera mayoritaria por Twitter, que resulta más accesible tanto por estar basado, fundamentalmente, en mensajes de texto, como por disponer de aplicaciones ad hoc que posibilitan una interacción adecuada con sus dispositivos de apoyo (habitualmente, un programa lector de pantallas). Facebook aparece, entre ellas, como una plataforma secundaria, inaccesible y farragosa, que si se llega a seguir es a la fuerza, por la participación en ella de otros amigos y no quedarse fuera del grupo. Elegir una plataforma de red virtual a contracorriente requiere una competencia tecnológica de partida, ya sea con Internet o telefonía móvil, y un nivel formativo que habitualmente es intermedio o alto.

Las personas con resto visual no expresan este rechazo frontal hacia Facebook por razones de estricta accesibilidad. Lo utilizan en ocasiones

4. Respecto a la accesibilidad de las plataformas de red social en Internet, puede consultarse el informe del Observatorio de la Accesibilidad TIC de Discapnet (Technosite, 20II). En la actualidad (junio de 20I4), Fundación Once realiza una nueva revisión de la accesibilidad de estas plataformas. a través de productos de apoyo específicos, como el magnificador de pantallas ZoomText. Eso sí, desde el primer momento expresan la incomodidad por la saturación de opciones e información, así como por los cambios periódicos de su apariencia y funcionamiento, con lo que supone de desorientación y sobresfuerzo de aprendizaje:

“[...] cuando ya has aprendido a manejarte un poco en el Facebook, resulta que te han cambiado las opciones, ya no encuentras dónde están” (GD ı. Discapacidad visual, persona con resto visual).

Entre los jóvenes y las personas con discapacidad intelectual participantes en el estudio (grupo este último integrado por jóvenes, en su mayoría), Tuenti ocupa un primer lugar en las preferencias, por su mayor sencillez de uso y su orientación hacia la comunidad de amistades, seguido por Facebook.

La accesibilidad es una barrera absoluta o supone un sobresfuerzo que lleva al abandono, y a perder oportunidades tanto en el terreno personal como profesional, a distintas personas con discapacidad.

\section{4. ¿Cómo se aprende a usar una red social? Pasos y dificultades}

Para abrir una cuenta en una red social en Internet, es necesario disponer previamente de una cuenta de correo electrónico. Para quien ya se desenvuelve en Internet con familiaridad puede resultar algo obvio, pero no para quienes empiezan o no disponen de esta cultura y competencia tecnológica, como pueden ser, en parte, los mayores. El uso del teléfono móvil ofrece también un punto de partida para entender la novedad que suponen las redes sociales virtuales.

Se encontraron dos caminos mayoritarios a la hora de aprender el uso de las RSI:

- $\quad$ El asesoramiento personal (el boca a boca). Un familiar o un amigo que ya usa una de 
las redes invita y orienta al principiante, acompañándole en los primeros pasos. Este camino es más frecuente entre los neófitos en Internet, las personas con menor familiaridad tecnológica y los mayores.

- El autodidactismo, por prueba y error ("cacharreando"). Se va descubriendo el uso de la plataforma sobre la marcha, probando las funcionalidades a través de la exploración. Este camino es más habitual entre aquellas personas con conocimiento previo de Internet.

Un punto crítico a la hora de abrir una cuenta en las plataformas de red social proviene de la falta de control y conocimiento suficiente sobre las opciones de privacidad y configuraciones de restricción. La desconfianza a este respecto es uno de los rasgos comunes en la imagen ambivalente de las plataformas de red social.

Se observó, sobre todo entre los mayores, una inseguridad en la propia destreza en este entorno tecnológico, y un temor a realizar operaciones, a dar datos por error o a autorizar inadvertidamente el uso inadecuado de los datos que se publican:

\footnotetext{
"Tengo un poco de miedo a pinchar en ciertos sitios. Cuando te dicen de registrado y de tal, cuidado con lo que metes y dónde lo metes. Usted da autorización para hacer esto, pero ahí no hay autorización ninguna. Si cogen los datos, pues ya están ahí” (GD 5. Mayores activos).
}

En caso de ser autodidacta, el riesgo consiste en que pueden obviarse zonas críticas, como la configuración adecuada de la privacidad, activar funciones no deseadas, o en todo caso, no sacar el máximo partido a la plataforma, por desconocimiento de sus posibilidades.

Parte de la atracción por las redes sociales en Internet se relaciona con su inmediatez y agilidad, valores reñidos con los manuales habituales. Algunas personas, en especial con conocimiento tecnológicos / de Internet intermedio o bajo, que suele coincidir con niveles formativos intermedios/bajos, echan en falta tutoriales más claros que se vinculen a las mismas redes, en otras palabras, que acompañen de manera fiable su uso "en tiempo real". Es decir, tutoriales coherentes con los valores que vuelven atractivas las redes.

\section{Las prácticas: "compartir la vida", informarse...}

Si algo caracteriza los usos de las redes sociales en Internet es su versatilidad: discurren de lo lúdico a lo profano, de la relación comunitaria con los amigos o familia al impulso de causas o la promoción profesional. Las prácticas dependen de la edad, el nivel formativo y la actitud ante las tecnologías.

\section{1. "Compartir la vida": espacio de socialización}

La comunicación interpersonal, contactar, hablar, participar de la vida del grupo, en los lazos comunitarios, familiares, de amistad, con conocidos con quienes se comparten aficiones e intereses, es la práctica que despierta mayores implicaciones emocionales y moviliza mayor energía en la discusión de los diferentes grupos.

La red virtual ofrece un espejo y canal complementario a la red social "presencial", capaz de amplificar el alcance de las comunicaciones llevadas a cabo por otros medios: cara a cara, teléfono, correo electrónico. Amplía el número de destinatarios del mensaje y de participantes en la comunicación -emisores y receptores, en suma- sobre un espacio común de encuentro: "el muro". La red virtual supera las distancias y evita, o complementa, los desplazamientos que en la ciudad pueden ser costosos en tiempo y dinero -no digamos entre ciudades o países- tanto más para las personas con movilidad reducida. Esta superación del espacio físico, hablar y mantener la cercanía y el sentido de proximidad con quien está lejos, 
es uno de los motivos más reiterados entre los participantes en el estudio.

La red multiplica, además, los estilos de mensaje que se pueden transmitir, abriendo un abanico a la medida de las orientaciones y preferencias entre los usuarios: desde "dar un toque" a escribir un mensaje personal, publicar fotografías, comentarlas o chatear, con diferente grado de implicación:

"Pues para ver fotos, estar comunicado con gente que no está cercana en estos momentos, y básicamente para eso. También se puede ligar en cierta manera" (GD 5. Jóvenes con discapacidad).

La red virtual se convierte en el espacio donde compartir tanto la cotidianidad del presente como lo extraordinario, representado en las fiestas, las vacaciones o el fin de semana ("recordar momentos"). Ambas vertientes actualizan la vida compartida de la comunidad y la presencia de sus miembros, que se vuelven visibles mediante mensajes textuales, fotos $\mathrm{u}$ otras formas de interacción.

Se encontraron pocos mayores con participación en las redes sociales virtuales. Aun entre aquellos con mayor familiaridad en el uso del ordenador e Internet, la novedad que suponen estas herramientas de comunicación parece un mundo, por su complejidad, riesgos percibidos y necesidad de conocimientos para configurar adecuadamente la privacidad y participar en ellas. Ahora bien, en las situaciones de "nido vacío" -viudedad, actividad o lejanía física de los hijos, que pueden vivir en otro punto de la ciudad o incluso en otro país- se hace uso de las redes sociales como una herramienta útil para mantener la comunicación cotidiana:

“-A mí no me gusta, vamos a ver, yo soy muy sociable y las redes sociales me parecen bien, pero no soy persona de la era informática, por mi edad. Entonces, yo prefiero hablar con la gente de viva voz. Es que esto me parece frío, ponerme ante una máquina y expresarle sentimientos.

\section{$[\ldots]$}

-Mi hijo está en Boadilla y tampoco vamos a estar todos los días viéndonos, pero cuando está ahí y ve que su madre está encendida, se pone en contacto conmigo" (GD 5. Mayores activos).

La red virtual, como la presencial, suele estar formada por contactos con y sin diversidad funcional. En algunos casos, en especial entre las personas con sordera, se observó una mayor orientación hacia comunicar con otras personas sordas.

Aunque la multifuncionalidad y el carácter multimedia supone barreras y con frecuencia una apariencia complicada, permite, por otro lado, elegir y combinar canales. Por ejemplo, la cámara web permite a las personas con sordera profunda comunicar a través de lengua de signos.

En la relación interpersonal, además de los aspectos señalados, como hablar/chatear con familiares y amistades salvando las distancias físicas, se mencionan otras actividades específicas, entre las que destacan:

- Cotillear. Las fotos publicadas, la puesta al día de las experiencias de cada cual, permite la participación vicaria en las experiencias de los demás, “compartir la vida”. Como parte de esta dimensión informal y lúdica del mirar y mirar(se), con frecuencia apareció en diferentes grupos el término "cotilleo", como "la salsa", es decir, el aspecto distintivo y divertido de la actividad en la redes.

El comentario y mirar la foto ajena es una manera más de reafirmar la pertenencia, de formar parte de algo. Se vive como una conducta al tiempo lúdica y culposa, con mayor componente de lo uno o lo otro, por lo que supone de participar en la intimidadpublicada de los demás, también por el supuesto tiempo perdido que esta actividad conlleva. Es, además, la manera de ponerse al día de la vida de antiguos contactos recuperados a través del canal virtual. 
Entre los más jóvenes, la curiosidad por la vida, los estilos y los hechos del grupo de pertenencia o referencia es un motivo inicial, un desencadenante de los lazos posteriores, al hablar, publicar otras fotos y mensajes. En el discurso se asocia al juego, que es otro motivo principal en este grupo etario en su relación con las redes. Ambas se relacionan, asimismo, desde esta caracterización ambivalente lúdicoculpable, por la adicción obsesiva que pueden llegar a generar ("te vicias”).

Los usuarios de las redes advierten, por otro lado, que lo publicado y compartido refleja "la mejor cara", la identidad más positiva de los demás (y de uno mismo). Esta presentación en positivo, puede llegar a ser tan creativa o alejada de lo que alguien conoce de una persona que es motivo de distanciamientos hacia las redes virtuales. Esta actitud se da sobre todo entre personas más proclives a la relación convencional cara a cara, menos familiarizadas con las TIC, por ejemplo, entre los mayores. Así como se asume el componente de ficción y versiones idealizadas del yo en la red virtual, hay diferentes disposiciones a la hora de participar en el juego.

- $\quad(\mathrm{Re})$ contactar. Se menciona con frecuencia la práctica de retomar el contacto con personas, amigos o conocidos de tiempo atrás a quienes se perdió la pista en el transcurso de la vida. Esta posibilidad es de las mejor valoradas entre los mayores: conocer esta opción supone ya un estímulo, y se presenta con alegría entre quienes han encontrado antiguos conocidos del trabajo, lugares en que se ha vivido o incluso familiares en otros países.

- Ligar. Las redes virtuales ofrecen también un canal para iniciar nuevas relaciones en el plano afectivo-sexual, esto es, para ligar. Por un lado, el espacio virtual permite, en mayor medida que el cara a cara, presentar un yo idealizado; segundo, se puede elegir a los integrantes de la propia red, así como gestionar las respuestas, la interacción, de manera menos inhibitoria o directa que en una llamada telefónica.

Por contra, la comunicación "ligera” mediante mensajes - proposiciones de amistad y más- puede suscitar dudas respecto al interés real de la invitación o la propuesta, y respecto a medios más directos en el intento de seducción ("¿habrá enviado este mismo mensaje a otras/os cinco más?”).

- Jugar. La relación interpersonal mediante el juego, tanto reglado/prefigurado mediante aplicaciones como informal (véase más abajo).

\subsection{Información instantánea y "a medida”}

Los usuarios con un nivel formativo medio-alto y edades intermedias descubren y aprovechan el potencial de las redes como medio de información a medida. Esta nueva manera de acceder a la información presenta los siguientes componentes:

- Ampliación y selección simultánea de fuentes y contenidos. A diferencia de la exploración de medios tradicionales, como un determinado periódico en línea, se lleva a cabo una selección por temas de interés y fuentes, que pueden ser otros usuariosprescriptores de contenido:

"Yo, sobre todo en Twitter, sigo a periódicos, gente que utilice mis mismas herramientas informáticas, que hablan de cosas que me interesan, a gente a la que, por ejemplo, le gusten los libros, la lectura. Ya no es tanto un patio de marujeo, como muchas veces la gente puede pensarse; es más como un punto de información y muy selectivo. Porque yo tengo un día que leo y un día que no leo, un día que busco temas muy específicos, por etiquetas" (GD I. Discapacidad visual).

- Información a medida de los propios intereses y prioridades: de pequeños emisores en el ámbito local, grupos por hobby, causas políticas, convocatorias de empleo, etc. 
- Acceder a las alternativas más próximas al estilo de comunicación preferente. Esta potencialidad se aprovecha en especial entre las personas sordas usuarias de lengua de signos, que través de las redes pueden encontrar a interlocutores con los cuales mantenerse al día.

- Conexión constante y "en tiempo real" a la información. A través de los dispositivos portátiles, como la telefonía móvil con acceso a Internet, se puede recibir información al momento, y actuar con ella, con mayor agilidad respecto a fórmulas previas vinculadas Internet, como la suscripción de contenidos mediante RSS.

Por estos rasgos, los usuarios más avanzados constatan una democratización en la generación y acceso a los contenidos a través de las redes. En el lado de los riesgos, cabría mencionar las nuevas formas de saturación que también trae la profusión de micromensajes, muchos de ellos -se reconoce- banales, lanzados sin pausa (ruido) ${ }^{5}$.

\subsection{Proyección laboral y actividad profesional}

A distancia de los anteriores usos y motivaciones, se señalan los motivos y utilidades laborales. Plataformas generalistas, como Facebook y Twitter, permiten seleccionar fuentes de información, personales o institucionales, para mantenerse al día respecto a la actividad profesional, o recibir información sobre cursos y ofertas de empleo. Permite constituir, en suma, redes de contacto sobre la base profesional.

5. Voces críticas ante la avalancha informativa de la conexión a las redes sociales, advierten acerca del riesgo de distracción. Como ejemplo, Nicholas Carr, exdirector de la Harvard Business Review y autor especializado en tecnología, observa cómo se "está erosionando la capacidad de controlar nuestros pensamientos y de pensar de forma autónoma. [...] La multitarea, instigada por el uso de Internet, nos aleja de formas de pensamiento que requieren reflexión y contemplación, nos convierte en seres más eficientes procesando información, pero menos capaces para profundizar en esa información y, al hacerlo, no sólo nos deshumanizan un poco, sino que nos uniformizan" (cit. en Celis, 20II).
Por otro lado, una plataforma de red social temática como LinkedIn permite darse a conocer y establecer un tejido de contactos -por afinidad profesional, entre conocidos a lo largo de la trayectoria, por actividad o sector- y de comunicación entre empresas.

Se señala el problema de su accesibilidad y gran esfuerzo que requiere su mantenimiento, en especial, entre las personas con ceguera, pero también desde otros perfiles.

\subsection{Presencia asociativa y ciberactivismo}

También se hace uso de las redes sociales como una herramienta sencilla, potente y de "coste cero" de cara a la difusión de las actividades asociativas y al impulso de campañas, en la línea del ciberactivismo. Dos de los participantes en el estudio, socios/responsables de la asociación Vive Desenfocado, orientada a dar a conocer las dificultades que afrontan las personas con esta discapacidad visual, cifran el éxito de la convocatoria y participación en las actividades por el alcance que ha tenido su presencia y actividad gracias a Internet y, más en concreto, a las redes sociales (Facebook):
"Nosotros, incluso, en Facebook tenemos creado un grupo, la asociación Vive Desenfocado, y bueno, tenemos bastantes seguidores y creo que es bastante útil. $\mathrm{Me}$ parece no solamente el hecho de que sea un entretenimiento, porque al mismo tiempo puedes charlar con los amigos, pero conoces a muchísima gente que de otra manera posiblemente no la conocerías” (GD I. Discapacidad visual).

Se percibe en las redes una posibilidad cercana para “crear grupos”, expresión que contiene tanto el significado literal ("virtual") de abrir una cuenta en la plataforma como el establecimiento de lazos, de relaciones de apoyo entre iguales, de impulso a una causa común.

Algunos de los participantes en el estudio han promovido campañas para reivindicar el voto accesible. Las redes sociales vuelven 
posible una difusión "viral” y una repercusión de las campañas más rápida y mayor que las herramientas previas de Internet. Se constata la viabilidad de conseguir objetivos políticos sin necesidad de los conocimientos especializados -y los costes- que podría exigir montar una campaña por medios convencionales.

"En las últimas elecciones hemos tenido voto accesible. Pero no sé por qué, para las municipales el voto accesible no está legislado. Entonces, mediante un movimiento que se ha hecho en nada de tiempo, se ha conseguido un montón de firmas; eso antes te costaba...” (GD I. Discapacidad visual).

\subsection{Jugar}

Los juegos que incluyen distintas plataformas ofrecen mayor atractivo a los más jóvenes, habitualmente estudiantes, en edades y roles sociales exentos de responsabilidades familiares y laborales. Los juegos se prueban y se abandonan, o se retoman como pasatiempo. Algunos de ellos reproducen en el espacio virtual juegos clásicos de mesa multijugador, como el parchís, y se juegan igualmente entre amigos/amigas como una manera de mantener el contacto, el vínculo, es decir, como en el juego convencional, salvando la distancia física. Por otro lado, la publicación de fotografías con enigmas ("adivina dónde estoy”), mensajes cortos imaginativos, la broma y el humor hacen de las redes un espacio lúdico informal, de cultivo de la amistad y los lazos familiares, por oposición al tiempo cotidiano del trabajo o el estudio, y es uno de los motivos de su uso.

Por concluir con las prácticas, en términos generales, se observó una marcada tendencia hacia el uso de las redes sociales desde el móvil, que el tiempo transcurrido desde la realización del estudio ha confirmado. Aun dentro de esta tendencia global, variables como el tipo de discapacidad, el nivel socioeconómicoformativo, la cultura tecnológica y la edad se correlacionan con preferencias en cuanto al dispositivo para consultar las redes sociales en Internet, y con frecuencia se combinan. Respecto al cuándo, tanto en la casa como en los desplazamientos urbanos y en otros tiempos muertos, el uso de las redes se concibe como un tiempo de descanso, de ocio, un contrapunto al trabajo que requiere menor concentración y atención que otras actividades.

\section{Imágenes sociales y actitud hacia las redes sociales en Internet}

Las imágenes sociales de las TIC y la actitud ante ellas, y de manera específica hacia las plataformas de red social -con sus peculiaridades, por un lado, y las diferentes culturas de la sociabilidad y el sentido de la privacidad en relación con las identidades, por otro-, determinan también las diferentes prácticas de participación, así como los distanciamientos y desincentivos, las barreras de diferente tipo ante estas redes virtuales. Estas percepciones y actitudes se relacionan también, en distinto grado, con niveles formativos y familiaridad ante las TIC y, de manera fundamental, con la edad.

\subsection{Dos ejes valorativos: percepción de la tecnología de red virtual y cultura de la sociabilidad}

Se pueden extraer dos ejes principales en la percepción y valoración de las redes virtuales:

- Las representaciones ante la tecnología de las plataformas de red social en Internet, que oscilan entre un polo negativo que condensa sus aspectos de barrera por razones de accesibilidad y usabilidad, la amenaza a la privacidad, su carácter "frío" o distante respecto a la interrelación "presencial"; y el polo positivo que destaca la oportunidad que ofrecen estas plataformas, según se ha visto en los apartados anteriores.

- La cultura de la sociabilidad, que va desde un polo más proclive a salvaguardar la 
privacidad o la intimidad del yo y evitar su exposición; hasta el otro polo, dispuesto a "compartir la vida" a través de las publicaciones de los "estados" -experiencias y emociones, contenidos informativos, promoción de causas, etc.- en un espacio común.

Ambos ejes se combinan en los discursos de los sujetos, situando su posición ante las redes virtuales. La Figura I recoge ambos ejes valorativos. El primero discurre entre la amenaza y la oportunidad en cuanto a la percepción de la tecnología; en el segundo, entre el sentido de intrusión y la participación horizontal, simétrica ("compartir”) respecto a la sociabilidad.

Al combinar ambos ejes valorativos, se observa la articulación de los diferentes discursos, esto es, de las diferentes imágenes y actitudes ante las redes sociales en Internet que sostienen distintos segmentos sociales. La Figura 2 recoge, a título de síntesis, estas posiciones.

Figura 1. Ejes valorativos en la percepción y actitudes ante las redes sociales virtuales

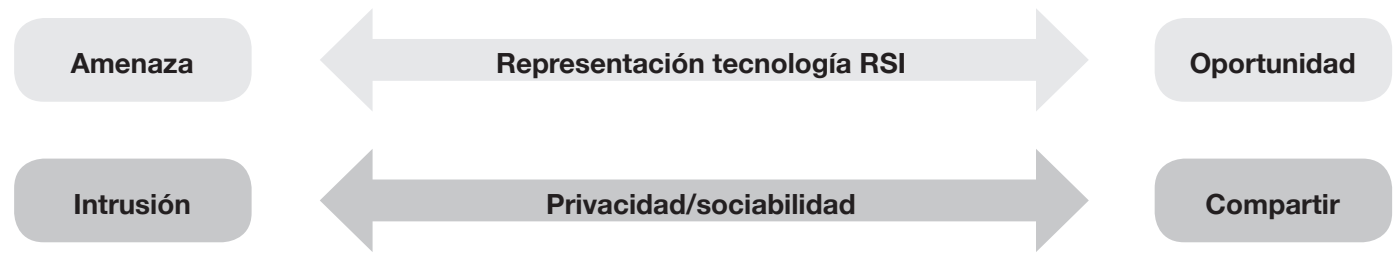

Fuente: Elaboración propia.

Figura 2. Combinación de ejes valorativos y discursos ante las redes sociales en Internet

"El único momento que lo veo negativo es cuando estamos dejando al descubierto cosas por desconocimiento"

- Riesgo de adicción

- Dificultades de aprendizaje

- Barreras de accesibilidad cosas

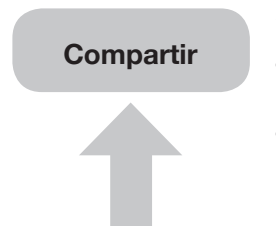

"Compartes fotos, compartes la vida"

- Participación comunitaria, interpersonal, fortalecimiento grupal.

- Abrir puertas: sortear obstáculos (arquitectónicos, sociales), acceder a la información y a nuevos contactos

- Información a medida y en tiempo real

- Nuevas posibilidades acción colectiva

- Proyección profesional

Amenaza

- Privacidad: puerta abierta por defecto

- Pérdida de control sobre tu vida privada (fotos, mensajes...)

- Ambivalencia de la identidad digital (ficción, falsedad)

- Desinterés por la vida ajena
Representación

tecnología RSI

- Sustituto del cara a cara, complemento útil y cómodo, aunque más frío

- Saturación informativa

Fuente: Elaboración propia. 
Las redes se perciben y practican, sobre todo al empezar, desde un fuerte sentido de ambivalencia o dualidad, por la tensión entre estos pares valorativos. Se perciben como una herramienta de proyección profesional, a pesar de sus barreras de accesibilidad; como un instrumento útil para comunicar y acceder a la información, aunque fría o generadora de "ruido". Dualidades que, más allá de la tecnología, se dan también en la "vida presencial": "el que se cree todo en Internet quizá se cree todo en la vida real”. (GD I. Discapacidad visual). La metáfora de la puerta expresa estas dualidades.

\subsection{La puerta: intersticio, oportunidad y defensa. Metáforas de la red virtual}

Una metáfora reiterada entre los participantes para comprender qué es, cómo se usa, los riesgos, etc. de una red social virtual es su comparación con una puerta. El campo metafórico comprende el hogar, como espacio privado del yo, y del otro lado, la calle, los otros, el mundo. Se sitúa como intersticio, zona de contacto, mixta, entre lo personal y lo público. Las posiciones oscilan entre quienes ven en las redes la oportunidad de ampliar contactos e información, y quienes, del otro lado, perciben demasiados agujeros en las plataformas como para aventurarse en ellas o prefieren mantener la privacidad, evitar mostrarse en este, en otras palabras, patio de vecinos que abarca el mundo entero.

Las redes como puerta al mundo se conciben como una herramienta para acceder a oportunidades sorteando diferentes obstáculos, tanto barreras del medio arquitectónico como de las distancias sociales. Es un lugar desde donde se pueden ver las "puertas" de los demás, tanto personas como entidades o grupos. Este sentido se relaciona con el acceso, la adquisición de nuevos contactos y conocimientos (fuentes informativas, contenidos), que permiten potenciar las estrategias personales, empoderar, aumentar el capital social. Multiplican, en otras palabras, el valor y posibilidades de Internet:

"Yo creo que las redes sociales han abierto muchísimas puertas. Creo que, para mí, es algo muy útil. Incluso cuando eres una persona que no tiene mucha movilidad, mucha autonomía, sobre todo aquí, en Madrid, que cuando yo llegué a Madrid decía que me iba a dar algo porque todo eran barreras. Es una puerta al mundo, nunca mejor dicho, una puerta al mundo" (GD I. Discapacidad visual).

La puerta de casa, el espacio de exposición del yo, donde se publica y se da cuenta del interior, de la privacidad, para que lo lean los demás: un cartel, referente análogo a la misma designación "muro", el espacio compartido de publicación de Facebook. Desde esta posición, se es favorable a exponer el ego, la identidad, atendiendo a las cautelas necesarias. El exterior puede ser amenazante: la puerta es también una frontera y una defensa del yo. La configuración de privacidad y la selección de "amigos" pasan a primer plano:

“-¿Yo sabe con qué comparo a Twitter? Usted pone un cartel en la puerta de su casa y usted se dedica a escribir, y todo el que pasa lo ve. $\mathrm{Y}$ usted lo que no tiene que hacer es ponerlo en la puerta de su casa, tiene que decir a qué personas se lo va a mandar, porque, si no, todo el mundo se va a enterar de lo que usted va a escribir.

-Eso es lo que me dice mi hijo" (GD 5. Mayores activos).

Entre las percepciones más distantes y los frenos a la hora de participar en las redes destaca aquella en que la privacidad no queda protegida por esta puerta, a pesar de las precauciones que se puedan adoptar. Los principales riesgos percibidos vienen de la (confusa y cambiante) política de registro de datos por parte de las plataformas (se apropian de lo publicado), la frágil salvaguarda de la privacidad y el uso inadecuado que, además, pueden hacer los demás o uno mismo, por desconocimiento. 


\section{Evolución de las redes en Internet y desafíos de acceso}

La tecnología asociada a la Web 2.0, a las redes sociales y a los dispositivos de acceso se revoluciona a ritmo vertiginoso. Entre los cambios transcurridos desde el momento de realización del estudio empírico (marzo-abril de 20II) y el presente (primeros meses de 20I4), cabe destacar:

- Las redes sociales se han universalizado, prácticamente, entre los internautas: en torno al $93 \%$ de los internautas españoles tiene al menos una cuenta activa en redes sociales (The Cocktail Analysis, 20I3; We Are Social, 20I4).

- Aunque se mantiene el ordenador como dispositivo de acceso más frecuente, se han extendido y ganan cada vez más protagonismo los dispositivos móviles, tanto teléfonos o teléfonos inteligentes como tabletas (The Cocktail Analysis, 2OI3).

- De acuerdo con la encuesta de The Cocktail Analysis (2013), Facebook sigue siendo la red líder absoluta $(83 \%$ de los entrevistados declara tener una cuenta activa), seguida de Twitter (42\%). Tuenti ( $27 \%$ ) y Google+ $(27 \%)$ se ven afectadas por importantes tasas de abandono. LinkedIn ( $8 \%$ ) se consolida como la red profesional e Instagram alcanza el I $2 \%$. Flickr $(5,2 \%)$, Foursquare $(4 \%)$ y Tumblr $(4 \%)$ se mantienen estables en su nicho. Aparecen novedades que no llegan a reconfigurar el mercado, como Pinterest (4\%) y Ask.fm (3\%).

- La aplicación de mensajería instantánea WhatsApp ha logrado un gran impacto como herramienta de comunicación en los teléfonos móviles. En este sentido, ha captado y cumple funciones de las plataformas de RSI (en especial, de Facebook y Tuenti), desplazándolas, a lo que sin duda contribuye su mayor sencillez.
De hecho, las actualizaciones de WhatsApp han tenido en cuenta las modificaciones planteadas por personas con discapacidad, que han contribuido a su mejora.

En relación con la accesibilidad, cabe apuntar, a juicio del autor ${ }^{6}$, como cuestiones relevantes y desafíos:

- La extensión de los dispositivos móviles para acceder a las redes sociales se explica por tres ventajas:

- Aun con sus restricciones, en general los teléfonos móviles, desde su elección (modelo, sistema operativo) a su configuración, proporcionan cada vez más opciones de personalización respecto a los ordenadores.

- Las aplicaciones nativas de móvil/ tableta para consultar y publicar en redes sociales son más sencillas (por ejemplo, tienen menos funcionalidades y publicidad) que las páginas web para la navegación desde el ordenador. Al ser más simples, resultan más intuitivas y parecen lograr mayor accesibilidad y aceptación.

- Por su pequeño tamaño y facilidad de consulta en cualquier lugar, el móvil se convierte en el dispositivo idóneo para acceder a las redes en momentos de ocio, desplazamientos en transporte público, etc.

- Diferentes plataformas de red social, en especial Twitter y Facebook, también Google+, han habilitado canales para notificar errores y reclamaciones de los usuarios en cuanto a accesibilidad ( $\dot{\text { son, }}$, por cierto, estos cauces accesibles?). En parte a causa de la presión de diferentes organizaciones y de la voz de los usuarios, las plataformas han aplicado medidas para mejorar la accesibilidad y políticas informativas al respecto. La accesibilidad es

6. Agradezco el diálogo con Jonathan Chacón, consultor experto en accesibilidad y desarrollador de aplicaciones accesibles. Las consideraciones del artículo son responsabilidad del autor. 
un requerimiento que va calando y cobrando presencia en la conciencia pública. Sin embargo, su aplicación sigue siendo desigual. Por la importancia de las plataformas de red social para la participación inclusiva, Fundación ONCE ha emprendido una nueva evaluación de su accesibilidad. En tanto se conocen sus resultados sistemáticos, en algunas plataformas se sigue observando escasa usabilidad, profusión informativa y funcional, y modificaciones sin mejora efectiva apreciable en la estructura. Esta saturación, ya señalada en el momento del estudio, supone una dificultad sobre todo para las personas con discapacidad intelectual, mayores o con baja familiaridad tecnológica, y un motivo de desplazamiento o consulta alternativa mediante aplicaciones móviles.

- A pesar de la extensión en población general de los teléfonos inteligentes y tabletas, y de su gama amplia, cabe considerar el factor precio como una dificultad para adquirir estos dispositivos, además del coste que supone el acceso a Internet. Aquí es preciso recordar la baja participación comparativa de las personas con discapacidad en el empleo, su mayor tasa de paro y cómo las condiciones de exclusión social son significativamente mayores entre las mujeres con discapacidad (tanto respecto a los varones con discapacidad como respecto a la población general) (Huete, 2013).

\section{Consideraciones finales}

La tecnología de redes sociales en Internet presenta perfiles paradójicos y también ambivalentes para las personas con discapacidad y mayores, aun teniendo en cuenta la diversidad de perfiles, no sólo funcionales, sino de edad y formativos -además de económicos-, variables que han destacado como las más influyentes en la percepción y uso de estas plataformas.
De entrada, para la mayoría de las personas con discapacidad -aun con reservas por lo que se refiere a aquellas con dificultades de comprensión- la actitud y adopción de las TIC digitales, en especial de Internet, es muy favorable, en cuanto que aporta autosuficiencia a la hora de acceder a contenidos y resolver gestiones, y de esta forma, ganar en participación social (ocio, trabajo, formación, etc.).

Los valores positivos de Internet, también su ambivalencia percibida, se multiplican en relación con las plataformas de red social. Permiten afianzar la red "presencial" de contactos y acceder a nuevas relaciones interpersonales, profesionales, vinculadas a problemáticas y causas: desde la pertenencia igualitaria y horizontal -“iguales ante la pantalla”- al ciberactivismo. Estas redes promueven la emergencia de nuevas prácticas en la relación interpersonal, obtener apoyo, información a medida, sensación de pertenencia a un grupo e identidad social. Permiten superar las distancias físicas, mantener relaciones de amistad y familiares en la misma ciudad, entre localidades y entre países.

Se da, por tanto, un impacto mutuo entre las redes sociales en Internet y las formas de relación offline. Amplían la capacidad de identificar a personas significativas por distinto motivo (afinidad y amistad -en primer lugar-, interés profesional, asociativo/político, ocio), contactar con ellas e incorporarlas a la red relacional. En este sentido, se puede decir que refuerzan el capital social de una persona y su inclusión comunitaria, según la metáfora de “abrir puertas". También se detectan riesgos de aislamiento e incluso adicción ("te vicias").

En líneas generales, las tecnologías de red social se han diseñado sin tener en cuenta los requerimientos de la diversidad humana, de la discapacidad, a la hora de interactuar con estas plataformas. Por la influencia y presión de diferentes organizaciones y de la voz de los usuarios, diferentes plataformas han aplicado medidas para mejorar la accesibilidad y políticas informativas al respecto. Han habilitado, 
además, canales, no siempre accesibles, para notificar incidencias y barreras en este aspecto. La escasa accesibilidad impide o dificulta, lo que exige esfuerzos extra y mayor competencia tecnológica para el uso de estas plataformas a parte de las personas con discapacidad. También los mayores encuentran dificultades semejantes, sobre todo para configurar el perfil y aprender el uso de estas tecnologías, que tienen un camino por delante para volverse más sencillas e intuitivas. Estos valores decantaron la elección, sobre todo entre los más jóvenes, de Tuenti. Hoy parecen haber movido a los usuarios de RSI hacia WhatsApp y las aplicaciones móviles, más sencillas $\mathrm{y}$, al parecer, accesibles.

Las posibilidades de empoderamiento y relación interpersonal que ofrecen las redes virtuales se ven limitadas tanto por sus barreras como, a pesar de la extensión en el uso de los teléfonos inteligentes y tabletas, por el precio de venta de estos dispositivos y el coste del acceso a Internet en ellos, considerando las condiciones de exclusión y vulnerabilidad social de parte de la población con discapacidad, en especial de las mujeres.

Como puntos que generan mayor distanciamiento respecto a las RSI, cabe señalar la ambivalencia en la presentación de las identidades digitales en Internet; la complejidad en la configuración de la privacidad; y el carácter intrusivo y la saturación que pueden llegar a generar, por su profusión de funcionalidades, mensajes y exceso de contactos.

La monitorización de la accesibilidad de las plataformas de red social, la misma voz de la ciudadanía, de los internautas, para notificar errores y mejoras necesarias resultan cruciales para potenciar el desarrollo y aprovechamiento de esta tecnología en beneficio de todas las personas. 
Bericat, E. (I996): "La Sociedad de la Información. Tecnología, cultura, sociedad”. Revista Española de Investigaciones Sociológicas, 76: 99-I $2 \mathrm{I}$.

Calvo-Fernández, A., et al. (20I I): Métodos de evaluación con usuarios, Universitat Oberta de Catalunya (en línea). <http://openaccess.uoc. edu/webapps/o2/handle/ı0609/9865>.

Celis, B. (20II): "Un mundo distraído" [entrevista con Nicholas Carr sobre su libro Superficiales. ¿Qué está haciendo Internet con nuestras mentes? (Taurus, 20II)], El País, 29 de enero (en línea). <http://www.elpais.com/articulo/ portada/mundo/distraido/elpepuculbab/2OI IOI 29elpbabpor_3/Tes>.

Cocktail Analysis, The (2013): $5^{a}$ Oleada Observatorio Redes Sociales (en línea). <http:// tcanalysis.com/blog/posts/el-7o-de-los-usuariosde-redes-sociales-se-muestran-receptivos-a-lapresencia-de-marcas-en-este-entorno>.

Echeverría, X. (2008): “Apropiación social de las tecnologías de la información y la comunicación”. Revista CTS, 4 (I): I7I-I82.

Huertas, S. (20I4): “¿Cuáles son las redes sociales con más éxito en España?”. Expansión, 30 de marzo (en línea). <http:// www.expansion.com/2014/03/30/empresas/ digitech/I396I $87893 \cdot \mathrm{html}>$.
Huete, A. (20I3): Pobreza y exclusión social de las mujeres con discapacidad en España, CERMI (en línea). <http://www. cermi.es/es-ES/Biblioteca/Paginas/Inicio. aspx? TSMEIdPub $=3$ I $5>$.

Lakoff, G. y Johnson, M. (I995): Metáforas de la vida cotidiana, Madrid: Cátedra.

Pascual, M. y Santero, I. (coords.) (2010): Transformemos el ocio digital. Un proyecto de socialización en el tiempo libre, Fundació Catalana de L'Esplai (en línea). <http://dim. pangea.org/revistaDIM2o/revista2oocio.htm>.

Technosite (20I I): Accesibilidad de plataformas de redes sociales. Diciembre 2010 , Observatorio de Accesibilidad TIC, Discapnet; Fundación ONCE (en línea). <http://www. discapnet.es/Castellano/areastematicas/ Accesibilidad/Observatorio_infoaccesibilidad/ informesInfoaccesibilidad/Paginas/ AccesibilidaddePlataformasdeRedesSociales. aspx>.

- (20I I): Enredar. Guía de Ayuda para las Redes Sociales, Fundación ONCE (en línea). <http:// www.enredar.fundaciononce.es>.

We Are Social (20I4): Social, Digital \& Mobile in Europe in 2014 (en línea). <http://wearesocial. net/blog/20 I $4 / 02 /$ social-digital-mobileeurope-20I $4 />$. 